Eduardo Rocha

\title{
ENSAIO SOBRE POLÍTICAS ESPONTÂNEAS E A PARALISIA DE CERTA ANTROPOLOGIA
}

\section{ESSAY ON SPONTANEOUS POLITICS AND THE PARALYSIS OF SOME ANTHROPOLOGY}

\section{Resumo}

Este ensaio é composto por uma problematização sobre o que o trabalho antropológico pode ou não poder fazer. A minha ideia é demonstrar vínculos morais e instantâneos das atividades antropológicas e desníveis de seriedade que temos diante de diferentes discursos. Ao longo do texto eu apresento uma situação singular do meu trabalho de campo junto aos Biólogos da Conservação que executam atividades de reflorestamento do Bioma Caatinga, em áreas degradadas pela Transposição do Rio São Francisco. Destaco nesta incursão etnográfica, elementos que marcam minha entrada em campo, consequentemente, elementos que constituem uma rede dos ganhos antropológicos a partir de elementos nos/dos trabalhos biológicos. Em seguida, eu demonstro como - incitado por um fazer moralizado e uma moral do preceder antropológico -, afasto-me dos meus interlocutores/biólogos por efeito de seus estranhamentos de atividades de comunidades tradicionais em condições semiáridas. Se reformulações das abordagens antropológicas, à luz de novos dados etnográficos, devem ser constante e constituinte, acredito que as inquietações contidas nesta comunicação configuram uma forma singular de conflito entre posicionamentos políticos da disciplina, historicamente edificados, e aparatos teórico-metodológicos, epistemologicamente colocados.

Palavras-chave: Política espontânea, Caatinga, Biologia da Conservação, Antropologia da Ciência e da Técnica

\begin{abstract}
This essay is composed of a problematization about what anthropological work can or can not do. My idea is to demonstrate moral bonds and instantaneous of the anthropological activities and unevenness of seriousness that we have before different speeches. Throughout the text I present a singular situation of my fieldwork with the Conservation Biologists who carry out reforestation activities of the Caatinga Biome in areas degraded by the São Francisco River Transposition. I highlight in this ethnographic incursion, elements that mark my entry into the field, consequently, elements that constitute a network of anthropological gains from elements in the
\end{abstract}


biological works. Then I demonstrate how - prompted by a moralizing and anthropological precedent morality - I move away from my interlocutors / biologists because of their strangeness from traditional communities activities in semi-arid conditions. If reformulations of anthropological approaches, in the light of new ethnographic data, must be constant and constituent, I believe that the concerns contained in this communication constitute a unique form of conflict between political positions in the discipline, historically constructed, and theoretical-methodological apparatus, epistemologically placed.

Key words: Spontaneous Politics, Caatinga, Biology of Conservation, Anthropology of Science and Technology

[...] a antropologia terá progredido suficientemente para que possamos construir uma antropologia de nós mesmos.

(Marcel Mauss: uma ciência em devenir - Louis Dumont)

Nietzsche dizia, sobre os grandes problemas, que eram como os banhos frios: é preciso entrar rápido e sair da mesma forma.

(Jamais fomos modernos - Bruno Latour)

Política espontânea foi um termo usado por Otávio Velho no artigo "Usos e abusos da diferença" $(2012)^{2}$ para problematizar um dos principais motivadores da antropologia, a saber, o que compreendemos como multiculturalismo. Diz respeito, grosso modo, ao vínculo que a disciplina mantém com a diferença e a diversidade

\footnotetext{
${ }^{1}$ Mestrando em Antropologia Social pela Universidade Federal do Rio Grande do Norte. E-mail: edurocha.ant@gmail.com

${ }^{2}$ Nesse texto, Otávio Velho trata de assuntos relacionados à história e à antropologia a partir de abordagens genealógicas inspiradas nos trabalhos de Friedrich Nietzsche. O peso e possibilidades do termo "política espontânea" são levantados por Velho, mas perpassam com certa timidez ao longo do texto, o que não quer dizer que nosso autor não esteja inquietado com os dispositivos morais do fazer antropológico. Gabriel Pugliese, em sua tese doutoral: História da Dietética: esboço para uma crítica antropológica da razão bioascética (2015), defendida recentemente na USP, problematiza os alcances e percalços da política interna da disciplina, que proíbe, corta, para ou barra - moralmente falando - a atividade antropológica diante de certos assuntos, por exemplo: quantos se habilitariam a conhecer mais e melhor um fascista? Quantos se habilitariam a conhecer mais e melhor um araweté?
} 
cultural enquanto referências para nossos estudos e reflexões. No bojo dessa perspectiva e dessa pluralidade, "fazer-falar o nativo" está associado às minorias e a um estilo de vida historicamente oprimido por formas de poder que ricocheteiam entre o colonialismo e o humanismo. Levar a sério o discurso do nativo é um meio pelo qual a antropologia se constitui cientificamente - por isso, política e moralmente - como área do conhecimento sensível às questões minoritárias. É mais ou menos assim que a antropologia, ao mesmo tempo que demarca seus interlocutores em seus estudos, delimita o que não caberia na forma de interlocução da construção de seus conhecimentos.

O que o trabalho antropológico pode ou não poder fazer constitui o espírito deste ensaio. A minha ideia é tentar problematizar veículos e vínculos morais e instantâneos das atividades científicas antropológicas a partir de desníveis de seriedade que temos diante de diferentes discursos. O que pretendo destacar aqui é a paralisia de nossa disciplina quando confrontada com questões que ferem os espaços do que historicamente a disciplina se propôs a defender. Haveria, nesse caso, pergunto, um procedimento que comporta o dispositivo antropológico de "fazer-falar os nativos" nos espaços em que se apresentam como discurso hegemônico? Como proceder à atividade antropológica quando o discurso do outro que nos dispomos a conhecer mais e melhor é moralmente repreensível, isto é, contra a "política espontânea" da disciplina? Como caminhar com uma antropologia quando seu foco de estudo é o que conhecemos como atividades majoritárias? Estudar temas minoritários seria menos problemático? (PUGLIESE, 2015). É possível fazer-falar um grande pesquisador da mesma forma que um pequeno agricultor e, assim, construir um deslocamento típico da reflexão antropológica? Se sim, pode a antropologia fazer-falar, simetricamente, cientistas e povos tradicionais?

Meus esforços em problematizar um dos princípios morais da disciplina - que são, vale lembrar, historicamente edificados -, mesmo que titubeando e carente de outros desdobramentos, fazem parte do próprio “jogo antropológico”. Que outra disciplina se compromete em pensar a si própria a partir da teoria constituída num 


\section{ENSAIO SOBRE POLITICAS ESPONTÂNEAS E A PARALISIA DE CERTA \\ ANTROPOLOGIA \\ Eduardo Rocha}

trabalho empírico? Não seria a autoantropologia ${ }^{3}$ um movimento inerente a qualquer postura antropológica séria e comprometida? Essas inquietações surgiram quando me deparei com uma situação de produção conjunta com meus interlocutores, em que eu, aprendiz de antropólogo, fui solicitado pelos cientistas que acompanho etnograficamente a construir um texto sobre como comunidades tradicionais fazem uso "inadequado" de recursos da caatinga. Para um melhor entendimento dessas inquietações, farei a seguir um pequeno enunciado sobre minha pesquisa e, após, detalharei os aspectos que me impossibilitaram de redigir uma comunicação que fere comunidades tradicionais e, por isso, fere o fazer moralizado e a moral do preceder antropológico. Demonstro aqui, portanto, como o trabalho conjunto entre pesquisador e pesquisados é impossibilitado pelos dispositivos morais da antropologia.

Em minha jornada ao longo dos caminhos antropológicos, tento alinhar minhas pesquisas com o que compreendo por Antropologia da Ciência e da Técnica $(\mathrm{ACT})^{4}$. Os interlocutores da minha pesquisa são biólogos da conservação que executam atividades de reflorestamento da caatinga em áreas degradadas por um dos maiores empreendimentos hídricos do país, a Transposição do Rio São Francisco. A tese que venho tentando desenvolver diz respeito ao deslocamento de agências das práticas humanas para as plantas da caatinga que se fazem atuantes na política de desenvolvimento nacional através das atividades dos biólogos. $\mathrm{Na}$ minha pesquisa, disponho-me a destacar distintos pontos de ações que se efetivam

\footnotetext{
${ }^{3}$ No artigo traduzido para o português como Os limites da autoantropologia (2014), Marilyn Strathern problematiza aspectos metateóricos do trabalho antropológico e sua relação com a teoria nativa. Explica a autora (e aqui se trata da minha interpretação) que autoantropologia - aquela que coloca no mesmo nível teoria nativa e teoria antropológica - chega a ser redundante, pois, de fato, o que o trabalho antropológico se propõe a fazer é levar a sério o discurso do nativo; que façamos isso, então.

${ }^{4}$ Postura teórico-metodológica desdobrada das noções de Antropologia Simétrica de Bruno Latour (1994). Compreendo a Antropologia da Ciência e da Técnica como a forma que alguns pesquisadores fazem a proposta de Latour sobre ciência e técnicas funcionar em suas pesquisas. Como exemplo, os trabalhos de Guilherme Sá (2013) sobre as subjetividades entre primatólogos e macacos muriquis; Jean Segata (2013) acerca de técnicas e controle de vida em animais de estimação; Stélio Marras (2014), problematizando a noção de seleção natural num laboratório de genética; Gabriel Pugliese (2012), que remonta de forma historiográfica às relações de gênero e à "descoberta" da radioatividade; Glaucia Oliveira (1999), lidando simetricamente com pescadores e usinas nucleares; Renzo Taddei (2010), que trata de capacidades de prever chuvas entre profetas da chuva e climatólogos, dentre outros.
} 
Eduardo Rocha

de forma relacional, tratando actantes de diferentes ontologias diferente e continuamente. A ideia é ver os diversos níveis de política na caatinga, assim como os diversos níveis de caatinga nas políticas, uma vez que são cortados por atividades científicas.

Desde meu trabalho de conclusão do curso de Bacharelado em Ciências Sociais na Universidade Federal do Vale do São Francisco (UNIVASF) ${ }^{5}$ busquei contatar os cientistas que executavam atividades de reflorestamento em situações de grandes projetos de desenvolvimento. Naquele momento, eu achava que acompanhar atividades científicas em situação de recuperação de biomas, no bojo do atual projeto de desenvolvimento do país, seria uma ótima porta de entrada para descrever e, assim, analisar simetricamente elementos da política (cultura?) e elementos da caatinga (natureza?) através de atividades científicas (técnicas?). Fazia (e faz) parte dos meus interesses, mesmo que a longo prazo, problematizar uma das principais e fundantes temáticas da nossa disciplina, a díade natureza/cultura. Os procedimentos da minha entrada em campo - tema relevante e bastante problematizado na história da disciplina - foram constituídos através de acordos que compõem um mútuo jogo de interesses políticos (com o perdão da redundância), no meu caso, de interesse da minha pesquisa antropológica sobre biólogos, plantas e políticas e da pesquisa dos biólogos da conservação ao longo da Transposição do Rio São Francisco, sendo, portanto, decisivos para compreender a construção das nossas redes e, consequentemente, os cortes nessas mesmas redes.

Dos mais diversos acordos que tive de fazer com os biólogos para que minha pesquisa pudesse ocorrer, lembro-me do compromisso de submeter ao "crivo" dos biólogos tudo o que, porventura, eu iria publicar. Ao que parece, esse tipo de acordo

\footnotetext{
${ }^{5}$ Pesquisa de título Peripécias da caatinga: quando plantas dialogam com políticas, orientada pelo Professor Doutor Gabriel Pugliese Cardoso (UNIVASF), submetida à banca avaliadora composta pelo Professor Doutor Delcides Marques (UNIVASF) e o Professor Mestre Levindo Pereira (UFMG), em 18/09/2014, como requisito para obtenção do título de Bacharel em Ciências Sociais pela Universidade Federal do Vale do São Francisco (UNIVASF). Levei, recentemente, os resultados desta inicial e incipiente pesquisa à $V$ Reunião de Antropologia da Ciência e da Técnica, ocorrida na Universidade Federal do Rio Grande do Sul (UFRGS) entre os dias 20 e 22 de maio de 2015. Ver: Brito, 2015.
} 
é bem comum no trabalho antropológico com comunidades em situação de risco ${ }^{6}$, no entanto, era do interesse de alguns dos biólogos ter algum controle das minhas atividades sobre as deles. Os biólogos nunca souberam de nenhum cientista social que se interessava em seguir atividades científicas; o que era comum em sua visão sobre o trabalho dos cientistas sociais era o trabalho de denúncia. Ter um antropólogo (digo: aprendiz de antropólogo) bisbilhotando documentos, perguntando os mais ínfimos detalhes de seu dia a dia, fotografando a forma como descansavam na sombra de uma retroescavadeira, dentre outros aspectos, causava um certo espanto. Assim, com o passar do tempo - pouco mais de um ano, na ocasião do meu trabalho de conclusão de curso -, os biólogos perceberam que minhas intenções eram estritamente científicas e que o cuidado para não trazer danos aos meus "nativos" fazia parte do meu trabalho, ou seja, não fazer da minha pesquisa um trabalho de denúncia era uma das minhas preocupações e isso trouxe alguma segurança para esses cientistas abismados pela forma como eu tentava fazer ciência ${ }^{7}$.

Os relacionamentos entre biologia e antropologia são aspectos que se mostram decisivos em minha pesquisa, por marcar outra nuance das "políticas espontâneas", porém, dessa vez, numa seara entre ramos distintos do conhecimento científico. O que é espontâneo é problemático e perigoso, carece de cautela e sensibilidade por parte da abordagem antropológica. Por mais que a ideia sobre o que é um antropólogo para outras ciências cause incômodos e marque, também, relações de poder historicamente edificadas, vi-me disposto a balizar e

\footnotetext{
${ }^{6}$ As negociações, conflitos e acertos sobre os processos de entrada em campo são um assunto que salta aos olhos. Michel Fischer (2009) faz uma compilação de várias etnografias sobre as mais diversas questões contemporâneas. A exemplo da pesquisa de Deepa Reddy, que acompanhou um grupo de cientistas que executavam mapeamentos genéticos e a comunidade dos imigrantes gujarati de Houston, sendo ela própria uma das pessoas que teriam de se submeter aos processos clínicos requeridos no experimento científico, por ser membro dos gujarati.

${ }^{7}$ A relação dos benefícios e malefícios que o trabalho antropológico pode causar aos "nativos" é outro tema que é cortado pelas "políticas espontâneas" da disciplina. Seria interessante ver até que ponto existem desníveis políticos sobre o que é "bom" e o que é "ruim" na minha pesquisa para os biólogos, mas admito não ter forças e tempo para debater esse assunto aqui, mas, comprometo-me a analisar à luz de dados etnográficos noutros espaços. Para um incrível relato sobre o cuidado, riscos, possibilidades e barreiras do trabalho antropológico em situação de possível "danos" aos interlocutores, ver a dissertação de mestrado do antropólogo Adalton Marques sobre crime, proceder e segurança nas relações entre ladrões (MARQUES, 2010).
} 


\section{ENSAIO SOBRE POLITICAS ESPONTÂNEAS E A PARALISIA DE CERTA \\ ANTROPOLOGIA \\ Eduardo Rocha}

ponderar meus interesses de pesquisas com o que a biologia pensa da antropologia, afinal, nesse momento, eu que estava querendo compreender as atividades dos biólogos, não o contrário. Para amenizar esse temor, amparei-me numa curiosa retomada da clássica separação entre Bios e Zoé feita por Giorgio Agamben. Sabese que Aristóteles sintetizava Zoé como vida comum entre os homens, animais e deuses, e Bios como forma relacional de viver em comunidade. Desse modo, Agamben (2010) explica que, desse ponto de vista, os antropólogos são os verdadeiros biólogos. Parece-me, portanto, uma confusão etimológica que o prefixo grego ßıos (Bios) apareça em referência à vida orgânica, colocando a biologia como a disciplina encarregada desses assuntos; não obstante, parece, como bem coloca Tim Ingold (2015), uma confusão na noção de vida.

Sentindo-me um pouco mais biólogo, procedi à pesquisa. Passando pelos ganhos dos desconfortos iniciais, minha pesquisa, que na época se resumia a uma leitura de documentos, relatórios de pesquisas, aparatos jurídicos, publicações científicas, dentre outras instâncias de registros dos biólogos - o que metodologicamente a antropologia poderia caracterizar como análise documental -, foi feita nos domínios de seus laboratórios. Tive acesso aos documentos mais bem guardados. Os biólogos deixaram claro que a única forma de ter acesso ao seu material era indo aos seus escritórios, laboratórios e outras instalações. Havia sempre uma sala climatizada para eu executar minhas pesquisas, supervisionado por algum técnico do laboratório que estivesse desocupado. Ter de me deslocar até os laboratórios dos biólogos não constituiu nenhum incômodo, a não ser minha tristeza por não ter tempo, forças e aprovação dos biólogos para fazer, assim como Latour e Woolgar (1997), uma etnografia de um laboratório.

Pouco tempo depois de pôr um "ponto final" naquela inicial incursão antropológica pelos documentos dos biólogos, recebi o convite do pesquisador chefe para ser coautor de um artigo. Foi após uma palestra sobre conservação da caatinga e políticas públicas no semiárido que recebi esse incrível convite. Falava o homem que já tinha escrito algo e que me enviaria em breve para eu fazer umas críticas. Após algum tempo, recebo o e-mail com um pequeno e curioso texto de título: $A$ ponte caiu ou nunca existiu?, já com nossos nomes (de)marcando a autoria do texto. 
No texto, o bioma caatinga era constantemente evocado com algo insubstituível e historicamente degradado. Em tom de lamento e decepção, diz meu parceiro biólogo que a caatinga está sendo degradada pela ação humana; plantas que ocorreram no passado já não aparecem mais. Os relatos de viajantes naturalistas sobre as caatingas e sertões são os últimos redutos desse pesquisador para rememorar a beleza de outrora. Árvores do gênero Podocarpus, que atualmente são típicas de locais com alta pluviosidade, já não compõem o cenário da caatinga destroçada pelas mudanças climáticas - curiosamente separadas da degradação causada pela ação humana -, ressalta o homem, amparado pelas suas próprias pesquisas: "os vazios ecológicos se estabeleceram antes das lacunas de conhecimento da biodiversidade serem suficientemente sanadas". Parece que o excesso de cultura em contato com a já não tão indomável natureza, para o biólogo da conservação, era problemático. Quanto mais parte da humanidade se movia pelas caatingas, menos era possível falar de uma caatinga genuína. Parecia inadmissível que um "bem natural" fosse destruído antes mesmo de ser "descoberto" pelos homens de ciência.

Tratava-se de um texto de denúncia, recheado de críticas ao cartesianismo, com pequenas alusões à Teologia da Libertação de Leonardo Boff, alusões um pouco maiores a Euclides da Cunha e a Darci Ribeiro e, como já mencionei, referências às suas próprias pesquisas de reflorestamento da caatinga. Como um texto escrito por um renomado biólogo da conservação caatinga ${ }^{8}$, era evidente a sua preocupação com esse bioma. Antes de o conteúdo do texto caminhar em direção à crítica às comunidades em condições semiáridas, inclusive, crítica à forma como as

\footnotetext{
${ }^{8}$ Ao longo do texto, evitei falar da identidade desse renomado biólogo da conservação, pois, dentre todas as políticas de acordos em campo, há uma política construída sob os alicerces da prudência disciplinar em não expor seus informantes. Por esse motivo, este ensaio, por si só, é problemático. Nesse momento, volto a uma de suas epígrafes e lembro como Bruno Latour (1994) evocou Nietzsche e sua forma de lidar com os grandes problemas da filosofia ocidental, expondo que sobre questões espinhosas é preciso ter prudência e não se perder no caminho, o que, não obstante, configura parte da "política espontânea" da disciplina. Como coloquei no início do ensaio, trato aqui do que o trabalho antropológico pode ou não pode fazer, então, ciente desse "metaperigo" - o perigo de fazer emergir os mais sutis dispositivos de construção de conhecimento -, aposto nos ganhos que essa honestidade pode proporcionar.
} 
Eduardo Rocha

políticas de Estado ${ }^{9}$ eram "inadequadas" na relação entre caatinga e pessoas catingueiras, o biólogo mostra-se bastante preocupado com o problema do conhecimento. Era evidente em seu relato a demonstração de que ocorre uma falha no diálogo entre políticas estatais, pessoas em condições semiáridas e demais elementos "naturais" da caatinga. Havia, segundo o biólogo, um problema na Didática de Comenius ${ }^{10}$; atividades como conferências, workshops e oficinas não possibilitavam transformações de velhos cenários de degradação da caatinga, consequentemente, de implantação do que ele chamou de "paisagens sustentáveis", por existirem incapacidades de diálogos e falta de tradução científica para as comunidades catingueiras. À sua maneira, esse cientista da conservação havia percebido, como já denunciava Michel Foucault (1999), um abismo entre "as palavras e as coisas".

Tudo o que porventura remetia aos problemas da construção do conhecimento científico, à ineficácia das aplicações de políticas de governo, à conservação da caatinga ou que me possibilitasse dar saltos em direção às questões internas da antropologia soava-me como uma manifestação da grandiosa lucidez do biólogo da conservação. Ao ler o texto e perceber o grau de comunhão entre nossos interesses científicos e políticos, como também a forma como os diferentes aparatos teóricos e metodológicos de nossas disciplinas poderiam alinhar nossas inquietações em alguma medida, vi-me encantado com a possibilidade da publicação conjunta com meus interlocutores biólogos da conservação da caatinga.

O episódio em que fui solicitado para redigir uma publicação conjunta diz muito sobre como, ao longo do tempo, os biólogos passaram a me ver e, consequentemente - com os devidos descontos, é claro -, a biologia passou a lidar com a antropologia. Tratava-se, para mim, de um ato de reconhecimento, algo como: "já que somos cientistas, podemos escrever algo juntos..."; a oportunidade era

\footnotetext{
${ }^{9}$ Acredito que uma incursão etnográfica sobre políticas, pessoas e caatinga poderia lançar maiores esclarecimentos sobre os encontros dos diferentes níveis de política e os diferentes modos de vida. A pesquisadora Ariane Vasques Zambrini, mestranda em Antropologia Social pela Universidade Federal de São Carlos, construiu um instigante relato sobre "a criação de nexos entre humanos, cabras, bodes e caatinga no sertão de Pernambuco" (ZAMBRINI, 2015).

${ }_{10}$ A Didática de Comenius (1966) é quase como se fosse uma bíblia para as ciências exatas e biológicas. Aparece como reduto de argumentação quando algum cientista (das ciências naturais) demonstra-se preocupado e conhecedor de aspectos didáticos e pedagógicos.
} 
única! Maurice Leenhardt, visto como parte essencial do começo do trabalho de campo na França (apud CAVIGNAC, 2006), já apontava a necessidade de escrita, reflexão e publicações conjuntas. Leenhardt foi um dos primeiros a destacar que pesquisador e pesquisado deveriam ocupar espaços semelhantes no trabalho antropológico. Recentemente, com a tradução do incrível $A$ Queda do Céu, do xamã yanomami Davi Kopenawa e do antropólogo Bruce Albert (2015), empolguei-me ainda mais sobre a possibilidade de construir artigos junto com meus interlocutores biólogos, problematizando, talvez nivelando essa relação, mas, ao certo, acrescentando novos dados na conturbada díade interna à antropologia: nós/eles, ainda mais por haver uma constante e constituinte tensão entre mim e os biólogos (admito que era mais uma tensão minha do que deles) pela histórica relação entre a biologia, área central nos planos políticos ocidentais (FOUCAULT, 2008), e a antropologia, área central nos planos religiosos ocidentais (MARQUES, 2015). Pontuar em que nível houve uma baliza entre nossas áreas de conhecimento me parecia um exercício bastante proveitoso.

Ao decorrer do texto, por outro lado, a argumentação sobre a integridade da caatinga parecia montar uma disputa entre diferentes movimentos de comunidades tradicionais e agricultores familiares. Nesse momento, recuei em relação ao texto do biólogo. Percebi que esse recuo tinha menos a ver com meus descuidos analíticos causados pela empolgação da publicação conjunta e mais com uma espécie de diretriz antropológica de não causar problemas para comunidades em situação de pobreza, ainda mais por não fazer parte de meus interesses de pesquisa naquele momento incursões etnográficas, por isso, conhecer um pouco mais os modos de vida de Comunidades de Fundo de Pasto, por exemplo.

Argumentava o biólogo, citando uma excelente experiência de beneficiamento de umbu em comunidades do sertão baiano ${ }^{11}$, que a criação de bode na caatinga impossibilitava o aparecimento de novos umbuzeiros e que, em breve, não restariam árvores aptas a produzirem frutos; a excelência no beneficiamento de umbu tinha prazo de validade. Por conta de uma atividade de criação de animais na caatinga,

\footnotetext{
${ }^{11}$ A COOPERCUC - Cooperativa Agropecuária Familiar de Canudos, Uauá e Curaçá - criada em 2004. Ver: <http://www.coopercuc.com.br/quem-somos/>. Acesso em: 16 jan. 2016.
} 
possibilitada por políticas estatais de convivência com o semiárido, meu interlocutor biólogo tecia sérias críticas às práticas daquelas comunidades. Criação de bodes e beneficiamento de umbu eram atividades que não poderiam ocupar os mesmos espaços. Vi esse jogo como uma forma de apontar a paralisia do trabalho científico de reflorestamento da caatinga, ocasionada pelo entendimento ou falta de entendimento, como bem colocou o biólogo, das políticas de estímulo à criação de caprinos na caatinga e das políticas de beneficiamento de produtos de origem vegetal. Colocar o umbuzeiro contra o bode me soava como uma curiosa forma de justificar o pouco alcance do conhecimento científico construído pelos biólogos da conservação da caatinga. Estava montado ali um "ringue", havendo, dentro deste: ciência versus comunidades tradicionais; bode versus umbu; animais versus plantas.

Quando cientistas que acompanho antropologicamente, de uma certa maneira, acusam práticas sociais minoritárias pela paralisia de sua ciência, a minha ciência também é paralisada. Instantaneamente, acionei elementos de uma moral antropológica que titubeia quando seus construtos podem ferir a integridade de pessoas em condições de fragilidade. Esse foi o tipo de política espontânea que me fez recusar a coautoria do artigo, fazendo-me cortar algumas redes que construí ao longo da minha incursão etnográfica com os biólogos da conservação. Pode ser que a paralisia do tipo de antropologia que venho tentando construir ocorreu por minha falta de compreensão das práticas daquelas pessoas. Faltavam-me segurança e entendimento sobre o que uma incursão etnográfica poderia proporcionar; era preciso compreender melhor o modo de vida daquelas comunidades para avaliar com mais coerência os ataques da ciência. Era preciso adentrar com a simetria noutros locais. No entanto, dispositivos morais da disciplina foram o suficiente para me fazer parar sem refletir, naquele momento, sobre os motivos do meu recuo.

Quanto à parte do texto em que o biólogo da conservação elenca os problemas do conhecimento, como também as ineficácias nas políticas de desenvolvimento do semiárido, sempre sustentados pelo coletivo de humanos e não humanos que suas atividades fizeram aparecer, a minha antropologia ganha espaço, afinal, construir redes que davam conta de elementos da caatinga e das políticas de desenvolvimento nacional é o principal disparador da minha pesquisa. O que me 
movia teórica e metodologicamente dizia respeito a uma "antropologia simétrica [...] do verdadeiro, assim como do falso, do científico, como do pré-científico, do central, como do periférico, do presente, como do passado" (LATOUR; WOOLGAR, 1997, p. 23). No entanto, quando o biólogo da conservação elenca os problemas de interpretação de pessoas em condições semiáridas, assim como suas incoerências produtivas, por manterem práticas agropecuárias danosas à prática agrícola, minha antropologia recua em direção a suas premissas fundamentais. Os dispositivos morais da disciplina barraram os dispositivos teórico-metodológicos da minha pesquisa. O histórico da disciplina, nessa ocasião, não potencializou a criação de minhas redes, pelo contrário, colocou-me uma dúvida sobre o quanto valeria a pena e o quanto seria correto proceder a minha pesquisa. Nesse momento, minha abordagem tornou-se assimétrica.

Se é simétrico falar dos vencedores e dos vencidos, das formas modernas e não modernas de conhecimento, de subjetivo e objetivo, de nós e eles; se é simétrico falar de plantas e políticas, de biologia e antropologia, de natureza e cultura, parece que é assimétrico criticar vencedores e vencidos, problematizar tanto sujeito quanto objetos, ou, ainda, descontruir argumentos de "pobres" e de "ricos" por essas bandas catingueiras. A simetria demonstra seus limites quando motivadores morais da antropologia revelam sua potência. A confusão reside nos níveis de disposição crítica que nossa disciplina evoca quando o problema se estende às formas de vida delegadas à marginalidade. Quando interpreto o que Strathern escreve sobre autoantropologia e como o "autoconhecimento também deve ser situado nas técnicas sociais de produção etnográfica-antropológica" (2014, p. 138), começo a perceber que meu recuo pode marcar uma autoantropologia de conveniência. Quando os feitos/fatos (LATOUR, 2002) da produção científica me possibilitam "tirar os móveis de lugar" e problematizar procedimentos significativos para o modo de vida ocidental, minha antropologia funciona bem; quando os feitos/fatos da produção científica causam danos a outras pessoas, minha antropologia não funciona bem. Pode parecer óbvio, simples e tautológico que a antropologia tenha dispositivos morais no seu bojo epistemológico e político que não permitam ataques a práticas sociais minoritárias, no entanto - e este é o principal 
objetivo deste ensaio -, o silêncio, o recuo e o medo de tocar nesses assuntos podem descaracterizar a abordagem antropológica de forma tão desastrosa quanto redigir um relato que cause problemas para comunidades tradicionais. Algum problema há, quando somente é possível proceder a crítica e problematização antropológica pelos caminhos do que historicamente é hegemônico. Algum problema há, quando somente é possível proceder a abordagens antropológicas boas para o que historicamente edificou a disciplina. Existem, de fato, problemas com a crítica antropológica.

Deparei-me, assim, com a seguinte situação: se levo a sério a simetria da minha pesquisa com os biólogos, posso ferir a integridade de comunidades tradicionais. Se levo a sério os dispositivos morais da disciplina, firo a integridade dos princípios de simetria generalizada (LATOUR, 1994). Se penso, como Strathern (2014), que cortes nas redes geram potências nas relações, reconhecendo que as ressonâncias de uma parada abrupta em minha pesquisa podem construir novos pontos de relacionamentos, corro o risco de desprezar o potencial das redes como dispositivo metodológico de construção conjunta de fatos. Se, por outro lado, levo a simetria às suas últimas consequências, corro o risco de "cuspir no prato que como", por assim dizer, ou seja, esbarro num tipo específico de ética antropológica. Se levei a sério minhas dúvidas e escrevi um ensaio teórico-metodológico expondo os problemas das colocações do biólogo, à luz da moral antropológica, não seria simétrico levar a sério o texto do biólogo e escrever um relato sobre as incoerências das práticas das comunidades tradicionais, à luz da simetria? Os limites de uma autoantropologia me parecem ser escopo da simetria, assim como os limites da simetria me parecem ser escopo da autoantropologia, pelo menos nos casos em que, guiado por uma abordagem antropológica, dediquei-me a entender a produção científica na caatinga e em que, a mando da moral antropológica, executei um corte nessa rede.

O que está em voga é um imbricado jogo político-epistemológico. Um embate epistemológico de reflexos morais e/ou um embate moral de reflexos epistemológicos. Parece que somente é conveniente desfazer os desníveis entre as teorias nativas e antropológicas quando a produção antropológica opera de forma a 
Eduardo Rocha

construir locais de discurso e poder para pessoas específicas. Se o que a antropologia estuda são as maneiras de as pessoas se relacionarem num mundo povoado por humanos e não humanos, parece que não é qualquer pessoa, qualquer não humano, muito menos qualquer mundo que pode ter voz através da abordagem antropológica. Não é possível fazer falar todo e qualquer nativo; há desníveis de natividades nas atividades antropológicas, e acredito que isso não seja novidade.

\section{REFERÊNCIAS}

AGAMBEN, Giorgio. Homo Sacer: o poder soberano e a vida nua I. Belo Horizonte: Editora da UFMG, 2010.

BRITO, E. N. Peripécias da Caatinga: quando plantas dialogam com políticas. In: REUNIÃO DE ANTROPOLOGIA DA CIÊNCIA E TECNOLOGIA, 5. Anais... Porto Alegre, 2015.

CAVIGNAC, Julie. Maurice Leenhardt e o início da pesquisa de campo na antropologia francesa. In: MOTTA, Antônio; GROSSI, Miriam (Org.). Antropologia francesa no século XX. Natal: Massangana, 2006. v. 1, p. 23-81.

COMENIUS, lohhannis. Didática Magna: tratado da arte de ensinar tudo a todos. Lisboa: Fundação Calouste Gulbenkian, 1966.

DUMONT, Louis. Marcel Maus - uma ciência em devenir. In: 0 Individualismo: uma perspectiva antropológica da ideologia moderna. Rio de Janeiro: Rocco, 1993. p. 179-200.

FISCHER, Michael M. J. Etnografia renovável: seixos etnográficos e labirintos no caminho da teoria. Horizontes Antropológicos, Porto Alegre, v. 15, n. 32, dez. 2009.

FOUCAULT, Michel. As palavras e as coisas: uma arqueologia das ciências humanas. Tradução de Salma Tannus Muchail. 8. ed. São Paulo: Martins Fontes, 1999.

FOUCAULT, Michel. O nascimento da biopolítica: curso dado no collège de France (1978-1979). São Paulo: Martins Fontes, 2008.

INGOLD, Tim. Estar Vivo: ensaios sobre movimento, conhecimento e descrição. Rio de Janeiro: Vozes, 2015. 
Eduardo Rocha

KOPENAWA, Davi; ALBERT, Bruce. A queda do céu: palavras de um xamã yanomami. Rio de Janeiro: Companhia das Letras, 2015.

LATOUR, Bruno; WOOLGAR, Steve. A vida de laboratório: a produção dos fatos científicos. Tradução de Ângela Ramalho Vianna. Rio de Janeiro: Relume Dumará, 1997.

LATOUR, Bruno. Jamais fomos modernos: ensaio de antropologia simétrica. Tradução de Carlos Irineu da Costa. Rio de Janeiro: Editora 34, 1994.

LATOUR, Bruno. Culto moderno dos deuses fe(i)tiches. Bauru: EDUSC, 2002.

MARRAS, Stélio. Recintos de Laboratório, Evolução Darwiniana e Magia da Obliteração? Reflexões em Antropologia da Ciência e da Modernidade. Ilha Revista de Antropologia, v. 15, p. 7-33, 2014.

MARQUES, Adalton. Crime, proceder, convívio-seguro: um experimento antropológico a partir de relações entre ladrões. 2010. Dissertação (Mestrado) PPGAS, Universidade de São Paulo, São Paulo, 2010.

MARQUES, Delcides. Um desafio ético-político para a antropologia da religião: a antropologia missionária protestante. In: REUNIÃO BRASILEIRA DE ANTROPOLOGIA, 29. Anais... Natal, 2014.

PUGLIESE, Gabriel. História da Dietética: esboço para uma crítica antropológica da razão bioascética. 2015. Tese (Doutorado em Antropologia Social) - PPGAS, Universidade de São Paulo, 2015.

PUGLIESE, Gabriel. Sobre o caso Marie Curie: a radioatividade e a subversão do gênero. São Paulo: Alameda/Fapesp, 2012.

SÁ, Guilherme. No mesmo galho: antropologia de coletivos humanos e animais. Rio de Janeiro: 7 Letras, 2013.

SEGATA, Jean. Os cães com depressão e os seus humanos de estimação. Anuário Antropológico, p. 177-204, 2013.

SILVA, Gláucia. Angra I e a melancolia de uma era: um estudo sobre a construção social do risco. Niterói: Editora da UFF, 1999.

STRATHERN, Marilyn. Os limites da autoantropologia. In: . O efeito etnográfico e outros ensaios. São Paulo: Cosac Naify, 2014. p. 133-158.

TADDEI, Renzo; GAMBOGGI, Ana Laura (Org.). Depois que a chuva não veio: respostas sociais às secas no Nordeste, na Amazônia e no Sul do Brasil. Fortaleza: FUNCEME/CIFAS, 2010. 


\section{INTER-LEGERE}

\section{ENSAIO SOBRE POLÍTICAS ESPONTÂNEAS E A PARALISIA DE CERTA \\ ANTROPOLOGIA \\ Eduardo Rocha}

VELHO, Otávio. Usos e abusos da diferença. In: HUFF JÚNIOR, Arnaldo Érico;

RODRIGUES, Elisa (Org.). Experiências e Interpretações do Sagrado: interfaces entre saberes acadêmicos e religiosos. São Paulo: Paulinas, 2012.

ZAMBRINI, Ariane. Laboro: a criação de nexos entre humanos, cabras, bodes e caatinga no sertão de Pernambuco. In: REUNIÃO DE EQUATORIAL DE ANTROPOLOGIA, 5.; REUNIÃO DE ANTROPÓLOGOS DO NORTE E NORDESTE, 14. Anais... 2015. 